\title{
Real Wage Dynamics and the Phillips Curve
}

\author{
Karl Whelan \\ Division of Research and Statistics \\ Federal Reserve Board*
}

December, 1999

\begin{abstract}
Since Friedman (1968), the traditional derivation of the accelerationist Phillips curve has related expected real wage inflation to the unemployment rate and then invoked markup pricing and adaptive expectations to generate the accelerationist price inflation equation. Blanchflower and Oswald (1994) have argued that microeconomic evidence of a low autoregression coefficient in real wage regressions invalidates this approach, a conclusion that has been disputed widely on the grounds that the true autoregression coefficient is close to one. This paper shows that the accelerationist relationship between the change in price inflation and the unemployment rate is consistent with any type of microeconomic real wage dynamics. However, these dynamics will determine how supply shocks affect inflation. Evidence on supply shocks and inflation points against the traditional real wage formulation. Implications for the recent behavior of the NAIRU are explored.
\end{abstract}

${ }^{*}$ This is a substantially revised version of my 1997 working paper "Wage Curve vs. Phillips Curve: Are There Macroeconomic Implications?". I am grateful to Daron Acemoglu, Olivier Blanchard, Charles Fleischman, Michael Kiley, Spencer Krane, and Calvin Schnure for comments. The views expressed in this paper are those of the author and do not necessarily reflect the views of the Board of Governors or the staff of the Federal Reserve System. Email: kwhelan@frb.gov. 
Robert Solow (1976) has said that any time is a good time to reflect upon the Phillips curve. This seems particularly true right now, given that the combination of low inflation and low unemployment in recent years has provoked a debate over the legitimacy of the Phillips curve framework, with some seeing a "New Economy" in which the Phillips curve has become irrelevant, and others seeing the recent period as a temporary anomaly brought on by fortuitous supply shocks and labor market developments. ${ }^{1}$

Recent years have also seen an important debate over the micro-foundations of the Phillips curve, stemming from the contributions of David Blanchflower and Andrew Oswald $(1994,1995)$. Blanchflower and Oswald have reported regressions for the level of real wages with coefficients well below one for the lagged real wage and pointed out that these results directly contradict the traditional formulation of the accelerationist Phillips curve, due to Milton Friedman (1968), which views expected real wage inflation as a function of the unemployment rate. They have suggested that "Conventional macroeconomics seems to be at threat from these results. They are consistent with the view that it is wrong to believe in a Phillips curve". 2 This conclusion has been challenged by a number of authors, including David Card (1995) and Olivier Blanchard and Lawrence Katz $(1997,1999)$, on the grounds that Blanchflower and Oswald's estimates of the coefficient on lagged real wages are biased downward.

This paper explores the relationship between real wage bargaining dynamics and aggregate price inflation. The paper has two purposes, relating to each of the recent strands of research on the Phillips curve. The first part of the paper explores the relationship between microeconomic real wage dynamics and aggregate inflation. I show that the legitimacy of the accelerationist Phillips curve does not rest upon Friedman's real wage inflation formulation: Under the traditional textbook assumption of a constant price markup over unit labor costs, all types of microeconomic real wage dynamics generate observably equivalent behavior for aggregate nominal wage and price inflation. However, once markups can vary, real wage dynamics play a role in determining the effect of these variations on price inflation. In particular, real wage dynamics will determine how supply shocks to import and energy prices, which are unrelated to domestic costs, affect aggregate consumer price inflation. Specifically, if workers bargain in terms

\footnotetext{
${ }^{1}$ See Gordon (1998), Katz and Krueger (1999), and Stock (1998) for three insightful contributions.

${ }^{2}$ Blanchflower and Oswald (1994).
} 
of real wage inflation, then supply shocks that erode the level of real wages will only temporarily raise price inflation, essentially because workers "let bygones-be-bygones". In contrast, if workers bargain in terms of the level of real wages, then such shocks will continue to impact wage bargaining and price inflation in later periods.

In light of these theoretical results, the second purpose of the paper is empirical. I show that the traditional specification of supply shock variables in empirical Phillips curves, such as those of Robert Gordon (1998), implicitly assumes the traditional Friedman real wage inflation formulation. I examine the effect of supply shocks on U.S. price inflation and conclude that the evidence points against this formulation. These results suggest an alternative specification for supply shock variables in inflation regressions. Empirical implementation of this approach points towards a more important role for supply shocks to energy and import prices in generating the recent inflation outcome than other investigations have found, and consequently a smaller role for labor market developments.

The contents are as follows. Section 1 discusses the traditional derivation of the accelerationist Phillips curve and briefly reviews the debate over the legitimacy of the standard assumption about real wage dynamics. Sections 2 and 3 present theoretical results on the relationship between microeconomic real wage dynamics and macroeconomic inflation equations. Sections 4 and 5 present the paper's empirical analysis. Section 6 concludes.

\section{The Traditional Derivation of the Phillips Curve}

\section{$1.1 \quad$ Theory}

Traditional derivations of the Phillips curve relationship between price inflation and the unemployment rate have started with a dynamic relationship between wages and unemployment and then used markup pricing to derive a price inflation formula. The

original relationship documented by A. W. Phillips related nominal wage inflation to unemployment. The modern accelerationist Phillips curve stems from Milton Friedman's (1968) insight that once workers bargained in terms of real wages, there could be no long-run tradeoff between unemployment and inflation. Friedman proposed an alternative approach: "Restate Phillips' analysis in terms of the rate of change of real 
wages - and even more precisely, anticipated real wages - and it all falls into place."

Algebraically, Friedman's theory can be expressed as

$$
w_{t}-p_{t}^{e}=w_{t-1}-p_{t-1}+\Delta x_{t}+\alpha-\beta u_{t}
$$

where $w, p$, and $x$ are the logs of the wage level, price level, and labor productivity respectively, and $u$ is the unemployment rate. Inflation expectations are assumed to be backward-looking. In the simplest case, this period's rate of price inflation is expected to equal last period's rate. ${ }^{3}$ Thus, the expected price level is determined by

$$
p_{t}^{e}-p_{t-1}=p_{t-1}-p_{t-2}
$$

Re-arranging equation (1) and substituting in the expression for the expected price level gives

$$
\Delta w_{t}=\Delta p_{t-1}+\Delta x_{t}+\alpha-\beta u_{t}
$$

This equation is translated into a price inflation formula with the assumption that firms set prices as a constant markup over unit labor costs, where $\mu$ is the log of the markup:

$$
p_{t}=\mu+w_{t}-x_{t}
$$

Differencing equation (4) and inserting into the wage inflation equation, we arrive at the standard accelerationist Phillips curve:

$$
\Delta p_{t}=\Delta p_{t-1}+\alpha-\beta u_{t}
$$

The change in inflation will be a positive function of the unemployment rate and inflation will only be stable if the unemployment rate equals the NAIRU, defined by $u^{*}=\frac{\alpha}{\beta} \cdot{ }^{4}$

\footnotetext{
${ }^{3}$ Note that this is not the same as $\Delta p_{t}^{e}=\Delta p_{t-1}$ which would mean that this period's expected price level minus last period's expected price level equals last period's inflation rate. This formulation would make little intuitive sense. Given that workers can presumably observe last period's price level, it is hard to see why they would instead use their previous (potentially incorrect) expectation of this variable in formulating an expectation of this period's price level.

${ }^{4}$ Of course, as is well known, the NAIRU terminology is probably the most notorious slipped derivative in economics; the Non-Accelerating Inflation Rate of Unemployment is really the Stable Inflation Rate of Unemployment. I will, however, stick with tradition, and the NAIRU, in this paper.
} 


\subsection{Evidence}

Equations (3) and (5) provide a good fit for the aggregate data on US price and wage inflation. Figures 1 and 2 , which show $\Delta^{2} p_{t}$ and $\Delta w_{t}-\Delta p_{t-1}$, respectively, charted against the unemployment rate over the period 1955-98 (using the value-added deflator for the nonfarm business sector excluding housing as $p$ and nonfarm business compensation per hour as $w$ ) give an illustration.

Despite this empirical success, questions linger over the legitimacy of the Phillips curve framework. In particular, David Blanchflower and Andrew Oswald (1994) have questioned the validity of the starting point of the above derivation, equation (1), which assumes that the expected rate of change of real wages depends on the unemployment rate. Using regional datasets, Blanchflower and Oswald estimated panel wage regressions of the form:

$$
w_{j t}=\rho w_{j, t-1}+\gamma X_{j t}+\alpha_{j}+\delta_{t}-\beta u_{j t}+\epsilon_{j t}
$$

where $X_{j}$ is a vector of variables describing the characteristics of the workers in region $j$ and $u$ is the unemployment rate. ${ }^{5}$ Blanchflower and Oswald reported estimates of $\rho$ of 0.3 and below, and interpreted this evidence as consistent with a simple "wage curve" relationship between the level of real wages and the unemployment rate. From these results, they concluded that equation (1) is incorrectly specified and that the macroeconomic Phillips curve is "a kind of misspecified aggregate wage curve", which "may be a mirage produced by a combination of overly aggregated data and inappropriate specification." 6

This conclusion has been widely disputed on the grounds that the reported estimates of $\rho$ are invalid. For instance, David Card's (1995) review of The Wage Curve questioned its method of estimating this coefficient and commented that "reports on the demise of the Phillips curve may be premature". Olivier Blanchard and Lawrence Katz (1997) also defend the traditional accelerationist Phillips curve by presenting evidence for the case that $\rho$ is close to one. Brian Bell (1997) obtains estimates suggesting that $\rho$ is about 0.8 .

\footnotetext{
${ }^{5}$ While these regressions were for nominal wage rates, Blanchflower and Oswald interpreted them as real wage regressions with the time effects picking up the effect of prices.

${ }^{6}$ Blanchflower and Oswald (1995).
} 
What are we to make of this wide range of estimates? That different empirical methodologies and datasets can give varying estimates of parameters of interest is unfortunately a common phenomenon in empirical economics. Moreover, economic theory gives us little help in deciding on sensible values for this parameter. For instance, a relationship between the level of real wages and the unemployment rate $(\rho=0)$ is consistent with theoretical models such as the Shapiro-Stiglitz formulation of efficiency wages. However, alternative approaches that allow for lagged wages to affect the current wage levels also seem plausible. For example, past wage levels may alter workers' "reservation" wages by shaping their assessment of what constitutes a "fair wage". Given this lack of consensus on the specification of real wage dynamics, it is important to know that macroeconomic accelerationist Phillips curve relationships such as (3) and (5), are in fact consistent with any value of $\rho$. The next section illustrates this proposition.

\section{The Constant Markup Case}

For the moment, let us keep the standard neo-Keynesian assumption that firms price as a constant markup over unit labor costs. For notational simplicity, assume each firm employs one worker and so the price of the good produced by firm $i$ is given by

$$
p_{i t}=\mu+w_{i t}-x_{i t}
$$

where $w_{i t}$ and $x_{i t}$ are the wage and productivity level of firm $i$ 's worker. We will return to the realism of the assumption of a constant markup over unit labor costs in the next section. For now, though, note that this price markup rule implies that the average real wage is proportional to average labor productivity:

$$
w_{t}-p_{t}=x_{t}-\mu
$$

where we have dropped the $i$ subscripts to indicate aggregated variables.

Consider now instead of the standard Phillips curve real wage formulation, equation (1), the following more general microeconomic bargaining relationship between real wages, lagged real wages, labor productivity, and the unemployment rate:

$$
\left(w_{i j}-p^{e}\right)_{t}=\alpha_{i}+\rho\left(w_{i j}-p\right)_{t-1}+\gamma_{0} x_{i t}+\gamma_{1} x_{i, t-1}-\beta u_{j t}+\epsilon_{i j t}
$$

where $w_{i j t}$ is the log wage of person $i$ living in region $j$ at time $t, p_{t}$ is the log of the aggregate price level, $u_{j t}$ is the unemployment rate in region $j$, and $\epsilon$ is a random 
shock. This real wage equation encompasses the traditional Phillips curve formulation $(\rho=1)$, the Blanchflower-Oswald wage curve $(\rho=0)$, and all intermediate cases. In principle, the parameter $\rho$ can be estimated from microeconomic data using a panel of observations on wages, unemployment rates, and proxies for labor productivity.

To derive the aggregate inflation equation, we start by aggregating equation (9). ${ }^{7}$ This gives us

$$
w_{t}-p_{t}^{e}=\alpha+\rho(w-p)_{t-1}+\gamma_{0} x_{t}+\gamma_{1} x_{t-1}-\beta u_{t}+\epsilon_{t}
$$

Substituting in the expression for the lagged aggregate real wage implied by equation (8) we get

$$
w_{t}-p_{t}^{e}=\alpha-\rho \mu+\gamma_{0} x_{t}+\left(\gamma_{1}+\rho\right) x_{t-1}-\beta u_{t}+\epsilon_{t}
$$

Now, inserting the accelerationist assumption for the expected price level from equation (2) gives

$$
w_{t}-p_{t-1}=\Delta p_{t-1}+\alpha-\rho \mu+\gamma_{0} x_{t}+\left(\gamma_{1}+\rho\right) x_{t-1}-\beta u_{t}+\epsilon_{t}
$$

Finally, using $w_{t}=p_{t}+x_{t}-\mu$, we get the following expression for aggregate price inflation:

$$
\Delta p_{t}=\Delta p_{t-1}+\alpha+(1-\rho) \mu+\left(\gamma_{0}-1\right) x_{t}+\left(\gamma_{1}+\rho\right) x_{t-1}-\beta u_{t}+\epsilon_{t}
$$

This equation relates the change in price inflation to the unemployment rate and current and lagged levels of labor productivity. Note, however, that in reality the $\log$ of labor productivity is a non-stationary $I(1)$ series. Thus, unless we impose the restriction that $\gamma_{0}-1=-\left(\gamma_{1}+\rho\right)$, implying that $x_{t}$ appears in the inflation equation in first-differenced terms, then the change in inflation will be a non-stationary series, implying that the gap between the expected and actual price levels will explode. Since this is an undesirable property, we impose this restriction throughout the rest of the paper.

\footnotetext{
${ }^{7}$ Technically, this aggregation only holds for geometric averages, since, in general

$$
\frac{1}{n} \sum_{i=1}^{n} x_{i}^{\rho} \neq\left(\frac{1}{n} \sum_{i=1}^{n} x_{i}\right)^{\rho}
$$

However, equality does hold precisely for our two extreme cases of $\rho=1$ and $\rho=0$ and so the aggregation also holds for arithmetic averages for these values.
} 
Given this restriction on the effect of productivity, we get the following aggregate inflation equation:

$$
\Delta p_{t}=\Delta p_{t-1}+\alpha+(1-\rho) \mu+\left(\gamma_{0}-1\right) \Delta x_{t}-\beta u_{t}+\epsilon_{t}
$$

Using $\Delta p_{t}=\Delta w_{t}-\Delta x_{t}$, we also have the following expression for nominal wage inflation:

$$
\Delta w_{t}=\Delta p_{t-1}+\alpha+(1-\rho) \mu+\gamma_{0} \Delta x_{t}-\beta u_{t}+\epsilon_{t}
$$

Two important points can be drawn from these equations. The first concerns the role of the microeconomic parameter $\rho$ in the macroeconomic equations. Both of the accelerationist relationships discussed earlier - equation (5), the price inflation Phillips curve relating the change in inflation to the unemployment rate, and equation (3), the wage-price Phillips curve - are consistent with any value of $\rho$. In particular, the microeconomic wage curve $(\rho=0)$ and macroeconomic accelerationist Phillips curve are completely compatible. ${ }^{8}$ More generally, since we have no independent information concerning $\alpha$ (the intercept in the wage equation), the parameter $\rho$ could not be identified from an aggregate inflation regression: All values of $\rho$ generate observably indistinguishable behavior for aggregate price and wage inflation. So, while re-stating A.W. Phillips's analysis in terms of the expected rate of change of real wages may have helped Milton Friedman express the intuition behind the accelerationist Phillips curve, the crucial assumptions underlying this relationship were that workers bargained in terms of expected real wages and had adaptive inflation expectations; the assumption about real wage dynamics was irrelevant.

The second point concerns the role of labor productivity. These Phillips curve relationships allow for a link between real wage bargaining and labor productivity. This contrasts with the results of Blanchard and Katz (1999) who have presented a model in which the traditional real wage bargaining formulation of $\rho=1$ can only hold if productivity has no effect on real wages. The apparent conflict has a simple explanation. Note that when $\rho=1$ our restriction that price expectational errors do not explode asserts that expected real wage growth can be related to the growth

\footnotetext{
${ }^{8}$ This point is not new. A demonstration of it is available, for instance, in the opening chapter of Layard, Nickell, and Jackman (1991). Also, Roberts (1997) has demonstrated the consistency of the wage curve with an alternative, rational expectations or "New Keynesian" version of the Phillips curve.
} 
rate of productivity, but not its level (the restriction becomes $\gamma_{0}=-\gamma_{1}$ ). ${ }^{9}$ However, the expected real wage equation employed by Blanchard and Katz did not include a lagged productivity term (implicitly imposing the restriction $\gamma_{1}=0$ ) and the omission of this term and the assumption of $\rho=1$ together rule out any relationship between bargained real wages and labor productivity (we must have $\gamma_{0}=\gamma_{1}=0$ ). Clearly, however, this result corresponds to a special case. Indeed, from equation (14), we see that combining this case of $\rho=1$ and $\gamma_{0}=0$ with the standard price markup rule implies an accelerationist Phillips curve featuring a strong negative relationship between productivity growth and the change in price inflation, a prediction that is not supported by the data.

Finally, note that productivity growth may or may not show up in the aggregate price inflation equation, depending on how labor productivity initially feeds into real wages, as determined by the parameter $\gamma_{0}$. This theoretical uncertainty over the role of productivity growth is also reflected in the empirical literature on the accelerationist Phillips curve. Some implementations, such as Gordon (1998), include such a productivity growth term; others don't.

\section{$3 \quad$ Variable Markups}

The assumption of constant markup pricing implies that microeconomic real wage dynamics are irrelevant for macroeconomic inflation dynamics. This result is important because simple markup pricing is a standard assumption underlying theoretical derivations of the Phillips curve, as well as "New Keynesian" models of inflation such as the staggered wage-setting models of Taylor (1980) and Fuhrer and Moore (1995). In reality, however, there is little reason to expect average price markups to be constant. In this section, I consider the source of fluctuations in average price markups and examine the implications of these fluctuations for Phillips curve analysis.

\footnotetext{
${ }^{9}$ When $\rho<1$ the restriction implies that in long-run equilibrium when expected prices equal actual prices, there is a unit pass-through from labor productivity to bargained real wages.
} 


\section{Interpretation of Price Markups over Unit Labor Costs}

The interpretation of the price markup over unit labor costs depends on the type of price index being used. I will focus on two alternatives: a value-added deflator and a consumption price index. The value-added deflator is the price per real unit of domestically produced final output. As such, this price index is the most natural fit for our two-equation wage-price model because the theoretically appropriate values for the wage rate $\left(W_{t}\right)$ and labor productivity $\left(\frac{Q_{t}}{L_{t}}\right)$ are directly observable in the domestic National Income accounts. When using a value-added deflator as $P_{t}$, the markup over unit labor costs is

$$
\exp (\mu)=\frac{P_{t}}{W_{t} / \frac{Q_{t}}{L_{t}}}=\frac{P_{t} Q_{t}}{W_{t} L_{t}}
$$

Thus, this markup is simply the inverse of the labor share of income. As can be seen in Figure 3, this income share is far from constant, although it has been a relatively stable variable over longer time periods, suggesting that for medium-run Phillips curve analysis of value-added price inflation, a constant markup may be a reasonable assumption.

One problem with using a value-added deflator is that workers are likely to bargain over real wages defined relative to a consumption price index. When we use a consumption price, the "markup" over domestic unit labor costs is a more complicated variable. Unlike the value-added deflator, which measures only the prices of domestically produced goods, the consumption bundle includes imports, prices for which may be set independent of domestic labor costs. Moreover, the prices of some domestically produced consumption goods will be influenced by prices for imported intermediate inputs, which are "netted out" in the calculation of the value-added deflator. ${ }^{10} \mathrm{~A}$ theoretical simplification that will be convenient later is to assume that a proportion $(1-\theta)$ of the consumption bundle is priced as a markup over domestic unit labor costs $\left(p_{t}=\mu_{t}+w_{t}-x_{t}\right)$, while the rest consists of imported goods or other goods such as food and energy for which prices are set exogenously to $p_{t}^{X}$ according to conditions in world markets and the exchange rate:

$$
\begin{aligned}
p_{t}^{C} & =\theta p_{t}^{X}+(1-\theta) p_{t} \\
& =\theta p_{t}^{X}+(1-\theta)\left(\mu_{t}+w_{t}-x_{t}\right)
\end{aligned}
$$

\footnotetext{
${ }^{10}$ This is not to say that value-added markups could not be affected by shocks to intermediate input prices. As Rotemberg and Woodford (1996) discuss, intermediate input prices have no effect on a value-added deflator only when firms are perfectly competitive.
} 


$$
=\mu_{t}+w_{t}-x_{t}+\theta\left(p_{t}^{X}-\mu_{t}-w_{t}+x_{t}\right)
$$

In this case, the implicit markup of the consumption price index over domestic unit labor costs reflects not only the allocation of domestic income but also exogenous supply shocks:

$$
\mu_{t}^{C}=p_{t}^{C}-w_{t}+x_{t}=\mu_{t}+\theta\left(p_{t}^{X}-p_{t}\right)
$$

\section{Markup Variations and the Phillips Curve}

Working though our previous derivations but this time letting the markup over unit labor costs vary over time, the price and wage inflation equations change to

$$
\begin{gathered}
\Delta p_{t}=\Delta p_{t-1}+\alpha+\mu_{t}-\rho \mu_{t-1}+\left(\gamma_{0}-1\right) \Delta x_{t}-\beta u_{t}+\epsilon_{t} \\
\Delta w_{t}=\Delta p_{t-1}+\alpha+(1-\rho) \mu_{t-1}+\gamma_{0} \Delta x_{t}-\beta u_{t}+\epsilon_{t}
\end{gathered}
$$

The substantive difference between these and the earlier equations is that, with variable markups, it is no longer true that different values for $\rho$ produce observably equivalent behavior for aggregate wage and price inflation. The effect of markup fluctuations on inflation will depend on the value of this parameter, a point that has been noted by Blanchard and Katz (1999). Consider the effect of a permanent increase in $\mu_{t}$. By definition, this shock depresses real wages relative to labor productivity. If $\rho=1$, then workers "incorporate" this negative shock to real wages into their future wage bargaining behavior and the increase in price inflation is temporary. In contrast, if $\rho<1$ then workers do not fully adjust their real wage bargaining positions, and the markup shock continues to affect price inflation in subsequent periods.

\section{Estimation}

How then can $\rho$ be estimated? While, in theory, it can be estimated from micro-data, in practice, as discussed earlier, such studies have produced a wide range of estimates. Moreover, estimates of $\rho$ from a specific micro dataset may not be representative of the average values for this parameter. An obvious alternative is to use the observable implications for macroeconomic data of variable markups to estimate the parameter. This is the approach taken here. 


\subsection{Estimation Using the Aggregate Markup}

Let us start with the most obvious route: Since $\mu_{t}$ is a time series, we can estimate the value of $\rho$ from either the wage or price inflation equation. In fact, wage inflation regressions of the same form as equation (20) have been estimated for a number of countries (e.g. OECD, 1997) with the $\mu_{t-1}$ term usually viewed as an "error-correction" term, the coefficient on which describes the speed with which real wages come into line with labor productivity. ${ }^{11}$ For the United States, the error-correction coefficient on $\mu_{t-1}$ usually has the "wrong" sign, in this case negative, a result emphasized recently by Blanchard and Katz (1999). In terms of our model, this implies a value of $\rho$ that is greater than one. This result is confirmed in columns (1) and (2) of Table 1, which estimate equation (20) using annual data on compensation per hour in the nonfarm business (NFB) sector as $w$ and the deflator for NFB output as $p$ in column (1) and the NIPA deflator for personal consumption expenditures (PCE) as $p$ in column (2). Note these regressions include more than one year of lagged inflation and impose the accelerationist restriction (which cannot be rejected) that the sum of the coefficients on lagged inflation equal one.

There are, however, a number of problems with this estimation procedure. First, the assumption that firms price with reference to unit labor costs is problematic. As can be seen in Figure 3, the variation in the value-added markup (inversed labor share) is mostly cyclical in nature, with labor share rising notably during each post-War recession. This cyclical pattern appears likely to be the result of firms pricing, not relative to unit labor costs but rather, as economic theory suggests, relative to marginal cost. The cyclical pattern for the markup over unit labor costs results from labor productivity being procyclical rather than real wages being countercyclical and there is now a great deal of evidence suggesting that procyclical productivity does not represent true variations in productive capacity but rather is the result of variable utilization of capital and labor. ${ }^{12}$ However, while this research explains why measured unit labor costs can

\footnotetext{
${ }^{11}$ In terms of the model presented here, this interpretation is only partially valid. Once we impose our restriction that price expectational errors do not explode, there is the following equation for the gap between expected real wages and productivity:

$w_{t}-p_{t}^{e}-x=\alpha+\rho(w-p-x)_{t-1}+\left(\gamma_{0}-1\right) \Delta x_{t}-\beta u_{t}+\epsilon_{t}$

However, the relationship between actual real wages and productivity is determined not by $\rho$ but by the price markup rule.

${ }^{12}$ See Basu (1996), Shapiro (1996).
} 
rise in recessions, it does not generally suggest the same pattern for marginal cost. For example, under-utilization of labor may raise unit costs but the absence of overtime pay may lower marginal cost, and this may explain why the observed average markup falls during cyclical downturns. ${ }^{13}$ One solution that has been adopted to deal with the problem of "spurious" cyclical productivity is to assume that the true pricing rule is closer to a markup over unit labor costs based on the trend rate of productivity. ${ }^{14}$ Columns (3) and (4) of Table 1 show, however, that this strategy does not materially change the results. The coefficients on $\mu_{t-1}$ obtained from this procedure still imply estimates of $\rho$ that are greater than one.

A second, more serious, problem with the direct estimation of $\rho$ from the wage inflation equation is simultaneity bias. The simple models developed here have assumed there is no correlation between any leads and lags of $\mu_{t}$ and $\epsilon_{t}$, the stochastic error in the wage equation. This assumption could be violated if there were some price rigidity, so that unexpected shocks to wages have a temporary effect in eroding markups. If such shocks are autocorrelated, then $\mu_{t-1}$ will be negatively correlated $\epsilon_{t-1}$, and through this with $\epsilon_{t}$, leading to downward biased estimates of the coefficient on $\mu_{t-1}$ in the wage inflation equation. Columns (5) and (6) confirm this hypothesis. Contemporaneous markups are strongly negatively correlated with errors in the wage equation, and once we include $\mu_{t}$ then the coefficients on $\mu_{t-1}$ switch sign from negative to positive. ${ }^{15}$ This simultaneity bias will also affect attempts to estimate $\rho$ from the price inflation equation. Indeed, this pattern probably explains the finding of Brayton, Roberts, and Williams (1999) that the markup over trend unit labor costs has a significant negative coefficient in price inflation regressions: While, ceteris paribus, an increase in the markup will have at least a temporary effect in raising price inflation, in reality the ceteris paribus assumption does not hold and positive shocks to the wage inflation equation result in higher price inflation and lower markups.

\footnotetext{
${ }^{13}$ Indeed, while measurement issues plague attempts to construct time series for marginal cost, the evidence suggests that markups over marginal cost are actually counter-cyclical. See Rotemberg and Woodford (1999) for a comprehensive review.

${ }^{14}$ Blanchard and Katz (1997) and OECD (1997) both adopt this approach when estimating equation (20).

${ }^{15}$ The table reports this regression using the markup over unit labor costs based on trend productivity. The results are almost identical if we use the actual markup.
} 


\subsection{Estimation Using Supply Shocks}

Our discussion of the consumption price markup suggest a solution to this simultaneity problem. Since part of the variation in this markup is due to supply shocks that are exogenous to shocks to domestic wages, we may be able to identify $\rho$ based on this source of variation. Inserting the expression for the consumption price markup (equation (18)) into the equation for price inflation (equation (19)), we get

$$
\begin{aligned}
\Delta p_{t}^{C}= & \Delta p_{t-1}^{C}+\alpha+\mu_{t}-\rho \mu_{t-1}+\left(\gamma_{0}-1\right) \Delta x_{t}-\beta u_{t} \\
& +\theta\left(p_{t}^{X}-p_{t}\right)-\rho \theta\left(p_{t-1}^{X}-p_{t-1}\right)+\epsilon_{t}
\end{aligned}
$$

If we use only variables affecting the consumption markup that are independent of domestic wages then, even if we omit the other sources of markup variation $\left(\mu_{t}\right.$ and $\left.\mu_{t-1}\right)$, we can still obtain unbiased estimates of $\rho$ as the ratio of the coefficients on the lagged and contemporaneous values of $\left(p_{t}^{X}-p_{t}\right)$, which is the ratio of "exogenous" prices to domestic output prices.

To implement this procedure, I chose two elements of the consumption bundle for which prices are likely to be set independently of domestic wage costs: imported consumer goods and energy. Using the NIPA price index for imported consumption goods as $p_{t}^{i m}$, the deflator for energy consumption as $p_{t}^{e n}$, and the NFB value-added deflator as $p$, I constructed the relative price terms $s_{t}^{i m}=p_{t}^{i m}-p_{t}$ and $s_{t}^{e n}=p_{t}^{e n}-p_{t} \cdot{ }^{16}$ Such relative price variables have long been used in empirical inflation regressions, such as those of Gordon (1998) and Staiger, Stock, and Watson (1997). However, these specifications have used the rate of change of these relative prices as the explanatory variable, implicitly imposing the restriction $\rho=1$.

Table 2 describes the results from estimating equation (21) for PCE inflation without the $\mu_{t}$ and $\mu_{t-1}$ terms and using these energy and import price variables as $p_{t}^{X}-p_{t}$. Three lags of inflation were used, with the coefficients constrained to sum to one. ${ }^{17}$ Column (1) shows the regression without any supply shock terms. Column (2) displays

\footnotetext{
${ }^{16}$ The import price index for consumer goods only exists from 1967 on. For earlier years, the index was "grown backwards" at the same rate as the price index for all imports. The energy deflator was constructed as a chain-weighted price index for consumer expenditures on electricity, gasoline, and fuel oil.

${ }^{17}$ Consumption price inflation was also adjusted to make the series methodologically consistent over time. The adjustments are the same as those used by Brayton, Roberts, and Williams (1999).
} 
the results for a traditional version of the regression, which imposes the restriction $\rho=1$ by entering the relative price variables in rate of change form. Column (3) reports the results from an unrestricted version of the regression, which estimates separate coefficients on contemporaneous and lagged levels of the relative price terms. The implied estimates of $\rho$ from the ratio of the coefficients on the lagged and contemporaneous values of the relative price terms are 0.81 (standard error, 0.08) for energy prices and 0.86 (standard error, 0.10) for import prices. ${ }^{18} \mathrm{~A}$ test of the restriction that $\rho=1$ is the correct specification gives an $F(2,35)$ statistic of 4.4 , rejecting the restriction at the 2 percent level of significance. In contrast, the restriction that the ratios of the coefficients on the lagged and contemporaneous values are identical for the import and energy price variables cannot be rejected (a Wald test produces a p-value of 0.69) and estimation of the regression imposing this restriction produces an estimated $\rho$ of 0.83 (standard error, 0.06).

\section{Supply Shocks and the NAIRU}

While the results in Table 2 suggest an estimate of $\rho$ that is statistically significantly different from the traditional formulation of $\rho=1$, these results are a lot closer to this assumption than the "wage curve" assumption of $\rho=0$. Moreover, statistical significance does not tell us whether the differences between real wage behavior characterized by $\rho=0.83$ and $\rho=1$ are of any economic significance. One possibility is that they imply different estimates of the NAIRU: The NAIRU is traditionally defined as that unemployment rate consistent with stable inflation in the absence of supply shocks, ${ }^{19}$ and these alternative estimates of $\rho$ imply different specifications for these supply shock variables. Simplifying our empirical model to be

$$
\Delta p_{t}=\Delta p_{t-1}+z_{t}+\alpha-\beta u_{t}+\epsilon_{t}
$$

where $z_{t}$ captures the effect of supply shocks on inflation, the standard estimate of the NAIRU is $-\frac{\alpha}{\beta}$ and the estimates of $\alpha$ and $\beta$ will depend on the specification of $z_{t}$. In practice, however, the difference between the implied estimates of the NAIRU from a

\footnotetext{
${ }^{18}$ These standard errors were derived using the delta method.

${ }^{19}$ To quote Robert Gordon: "The standard concept is the "no-supply-shock" NAIRU .... Without this qualification, the NAIRU would jump around as supply shocks arrived and departed, which is not what most economists are trying to convey when they speak of the natural rate of unemployment."
} 
specification based on the traditional $\rho=1$ supply shocks and one based on the $\rho=0.83$ supply shocks is tiny: The NAIRUs from the models estimated in Columns (2) and (3) of Table 2 are 6.22 percent and 6.21 percent, respectively.

Beyond these long-run NAIRUs, however, the alternative estimates of $\rho$ imply different stories for how supply shocks have affected inflation over time. Figure 4 shows the levels of the two relative prices used in the regressions in Table 2 and Figure 5 shows the estimated combined effects of these variables on PCE price inflation from the regressions in Columns (2) and (3). The estimated effect from the unrestricted specification (with $\rho=0.83$ ) depends on both the level and the change in the relative prices of energy and imports, and it suggests that supply shocks had a more pronounced effect in lowering inflation during the 1960s and then in raising it during the early and mid-1980s, when relative energy prices were declining but still at a high level. Not surprisingly, these different specifications also imply different patterns for the residuals in the Phillips curve regressions. The $\rho=0.83$ specification has smaller negative residuals in the 1960s and smaller positive residuals in the 1980s.

This different pattern of residuals has implications for efforts to model changes over time in the NAIRU. Once this is allowed for, the underlying model for inflation becomes

$$
\Delta p_{t}=\Delta p_{t-1}+z_{t}+\alpha-\beta\left(u_{t}-u_{t}^{*}\right)+\eta_{t}
$$

and the residuals from the estimated model, equation (22), will depend on both the stochastic variation in the price inflation equation $\left(\eta_{t}\right)$ and the fluctuations in the timevarying NAIRU, $u_{t}^{*}$. The research of Staiger, Stock, and Watson (1997) and Gordon (1998) has focused on using the pattern of residuals to estimate a time series for the timevarying NAIRU, employing assumptions about the smoothness of the time-series for the NAIRU to split the residual into its NAIRU-related and other components. Figure 6 shows the results from applying one of these methods, the cubic spline approach of Staiger, Stock, and Watson, to the Phillips curve specifications in Columns (2) and $(3) .^{20}$

The pattern for the time-varying NAIRU estimated for the traditional $\rho=1$ spec-

\footnotetext{
${ }^{20}$ This approach models the time-varying NAIRU by adding a cubic spline in time to the Phillips curve regressions, splitting the sample into three periods of equal length, and then estimating separate coefficients for the spline in each period subject to the constraint that the level and first-derivatives of the splines are equal at the two "knot" points.
} 
ification falls a little during the early 1960s, then rises steadily until the mid-1980s before dropping sharply in the 1990s, with the 1998 value of 4.9 percent being a full 2 percentage points lower then the mid-1980s peak. While the exact magnitude of these variations are arbitrary and dependent on the specific smoothness criteria used, this pattern is also evident in other estimates of the time-varying NAIRU based on the traditional supply shock variables, such as those of Gordon (1998). In contrast, the time-varying NAIRU for the $\rho=0.83$ specification shows a notably different pattern, remaining within a narrow corridor between 6.0 and 6.4 percent for almost every year between 1960 and 1994, and then dropping sharply thereafter.

Qualitatively, these two NAIRU series tell a similar story about the 1990s. Even accounting for the effect of supply shocks, the combination of low inflation and low unemployment seen in recent years is likely to be due, at least in part, to labor market developments that have lowered the natural rate of unemployment. However, the two series point to different magnitudes for this decline, with the alternative $(\rho=0.83)$ NAIRU series declining by only half as much since the mid-1980s as the traditional $(\rho=1)$ series. This is of particular interest given the conclusion of Katz and Krueger (1999) that recent labor market developments such as demographic shifts, the increase in temporary employment, and the growth in the prison population, can only explain about half of the apparent decline in the NAIRU estimated from traditional Phillips curves. The alternative NAIRU series also points to a somewhat different interpretation of the historical relationship between inflation and unemployment over the past 40 years. The apparently low NAIRUs of the 1960s and high NAIRUs of the 1980s may have been due in part to the effect of supply shocks on wage bargaining. Despite declining relative prices for energy and import prices in the 1980s, the levels of these series were still quite high, and the consequent effect on real wages led to raised "wage push" pressure. The 1960s, and to a lesser extent, the 1990s, saw this process working in reverse. 


\section{Conclusions}

Starting with Milton Friedman's famous presidential address, the standard derivation of the accelerationist Phillips curve has taken as its starting point the assumption that the expected rate of change in real wages is a function of the unemployment rate. Much recent debate over the legitimacy of the Phillips curve relationship has focused on whether this is a reasonable assumption. This paper has examined the role of real wage dynamics in determining aggregate inflation and shown that the Phillips curve relationship between the change in price inflation and the unemployment rate does not depend on a specific assumption about the pattern of autoregression in micro-level real wages. Since a particular formulation of real wage dynamics is not required to obtain the accelerationist Phillips curve, theoretical critiques of this relationship should probably instead focus upon another assumption crucial to its derivation, adaptive inflation expectations, and whether a rational alternative can capture the autoregression present in empirical inflation regressions. Fuhrer (1997) and Roberts (1998) are two recent papers in this vein that come up with mixed conclusions on the relative importance of forward and backward-looking expectations.

These results do not mean that real wage dynamics are unimportant. They will determine the effects of supply shocks on price inflation, and thus the appropriate specification of supply shock variables in empirical Phillips curve regressions. The empirical evidence on supply shocks and inflation presented in this paper suggests that while real wage bargaining likely has an important autoregressive component, the usual baseline case of $\rho=1$ appears to be incorrect. These results may help to explain some of the large swings in the estimated time-varying NAIRUs based on Phillips curves with traditionally-specified supply shock variables.

\section{References}

[1] Basu, Susanto (1996) "Cyclical Productivity: Increasing Returns or Cyclical Utilization" Quarterly Journal of Economics, 111, 719-751.

[2] Bell, Brian (1997). "Wage Curve or Phillips Curve?", Nuffield College, Oxford. 
[3] Blanchard, Olivier Jean and Lawrence Katz (1997). "What We Do and Do Not Know About the Natural Rate of Unemployment", Journal of Economic Perspectives, 11:1, 51-72.

[4] Blanchard, Olivier Jean and Lawrence Katz (1999). "Wage Dynamics: Reconciling Theory and Evidence", American Economic Review, 89, May, 69-74..

[5] Blanchflower, David and Andrew Oswald (1994). The Wage Curve, Cambridge: MIT Press.

[6] Blanchflower, David and Andrew Oswald (1995). "An Introduction to the Wage Curve", Journal of Economic Perspectives, 9:3, 153-167.

[7] Brayton, Flint, John M. Roberts, and John C. Williams (1999). What's Happened to the Phillips Curve?, Federal Reserve Board Finance and Economics Discussion Series Paper No. 1999-49.

[8] Card, David (1995). "The Wage Curve: A Review", Journal of Economic Literature, 33, 785-799.

[9] Fuhrer, Jeffrey (1997). "The (Un)Importance of Forward-Looking Behavior in Price Specifications", Journal of Money, Credit, and Banking, 29, 338-350.

[10] Fuhrer, Jeffrey and George Moore (1995). "Inflation Persistence", Quarterly Journal of Economics, Vol. 110, 127-159.

[11] Friedman, Milton (1968). "The Role of Monetary Policy", American Economic Review, 58, 1-17.

[12] Gordon, Robert J. (1998). "Foundations of the Goldilocks Economy: SupplyShocks and the Time-Varying NAIRU", Brookings Papers on Economic Activity, 2, 297-333.

[13] Katz, Lawrence, and Alan Krueger (1999). "The High-Pressure U.S. Labor Market of the 1990s", Brookings Papers on Economic Activity, 1, 1-65.

[14] Layard, Richard, Stephen Nickell and Richard Jackman (1991). Unemployment: Macroeconomic Performance and the Labour Market, Oxford: Oxford University Press. 
[15] OECD (1997). Employment Outlook, Paris: Organization for Economic Cooperation and Development.

[16] Roberts, John M. (1997). The Wage Curve and the Phillips Curve, Federal Reserve Board Finance and Economics Discussion Series Paper No. 1997-57.

[17] Roberts, John M. (1998). Inflation Expectations and the Transmission of Monetary Policy, Federal Reserve Board Finance and Economics Discussion Series Paper No. 1998-43.

[18] Rotemberg, Julio and Michael Woodford (1996). "Imperfect Competition and the Effects of Energy Price Increases on Economic Activity", Journal of Money, Credit, and Banking, 28, 549-577.

[19] Rotemberg, Julio and Michael Woodford (1999). "The Cyclical Behavior of Prices and Costs", in John Taylor and Michael Woodford (eds.), The Handbook of Macroeconomics, North-Holland.

[20] Shapiro, Matthew (1996). "Macroeconomic Implications of Variations in the Workweek for Capital", Brookings Papers on Economic Activity, 2, 79-119.

[21] Solow, Robert (1976). "Down the Phillips Curve with Gun and Camera", in Inflation, Trade, and Taxes: Essays in Honor of Alice Bourneuf, D. Belsley (ed.), Columbus: Ohio State University Press.

[22] Staiger, Douglas, James Stock, and Mark Watson (1997). "How Precise Are Estimates of the Natural Rate of Unemployment", in Christina Romer and David Romer (eds.) Reducing Inflation, Chicago: University of Chicago Press.

[23] Stock, James (1998). "Comment", Brookings Papers on Economic Activity, 2, 334341.

[24] Taylor, John (1980). "Aggregate Dynamics and Staggered Contracts", Journal of Political Economy, Vol. 88, 1-23. 
Table 1: Wage Inflation and the Average Price Markup

Dependent Variable: $\Delta w_{t}-\Delta p_{t-1}$

\begin{tabular}{|l|c|c|c|c|c|c|}
\hline & $(1)$ & $(2)$ & $(3)$ & $(4)$ & $(5)$ & $(6)$ \\
\hline$\mu_{t}$ & & & & & $\begin{array}{c}-0.59 \\
(0.15)\end{array}$ & $\begin{array}{c}-0.59 \\
(0.12)\end{array}$ \\
\hline$\mu_{t-1}$ & $\begin{array}{c}-0.11 \\
(0.16)\end{array}$ & $\begin{array}{c}-0.16 \\
(0.04)\end{array}$ & $\begin{array}{c}-0.12 \\
(0.10)\end{array}$ & $\begin{array}{c}-0.18 \\
(0.05)\end{array}$ & $\begin{array}{c}0.33 \\
(0.14)\end{array}$ & $\begin{array}{c}0.39 \\
(0.13)\end{array}$ \\
\hline$u_{t}$ & $\begin{array}{c}-0.54 \\
(0.26)\end{array}$ & $\begin{array}{c}-0.65 \\
(0.20)\end{array}$ & $\begin{array}{c}-0.47 \\
(0.20)\end{array}$ & $\begin{array}{c}-0.55 \\
(0.18)\end{array}$ & $\begin{array}{c}-0.31 \\
(0.18)\end{array}$ & $\begin{array}{c}-0.43 \\
(0.14)\end{array}$ \\
\hline$u_{t-1}$ & $\begin{array}{c}-0.48 \\
(0.25)\end{array}$ & $\begin{array}{c}-0.37 \\
(0.24)\end{array}$ & $\begin{array}{c}-0.40 \\
(0.23)\end{array}$ & $\begin{array}{c}-0.42 \\
(0.22)\end{array}$ & $\begin{array}{c}-0.44 \\
(0.20)\end{array}$ & $\begin{array}{c}-0.39 \\
(0.17)\end{array}$ \\
\hline Price & $\mathrm{NFB}$ & $\mathrm{PCE}$ & $\mathrm{NFB}$ & $\mathrm{PCE}$ & $\mathrm{NFB}$ & $\mathrm{PCE}$ \\
\hline $\begin{array}{l}\text { Trend } \\
\text { Productivity }\end{array}$ & No & No & Yes & Yes & Yes & Yes \\
\hline $\bar{R}^{2}$ & 0.566 & 0.643 & 0.601 & 0.696 & 0.712 & 0.811 \\
\hline
\end{tabular}

Standard errors in parentheses. Sample is annual data over 1955-98. $w$ is the log of the nonfarm business compensation per hour; NFB signals that $p$ is the log of the value-added deflator for the nonfarm business sector, PCE signals that $p$ is the log of the deflator for personal consumption expenditures; $\mu$ is the log of the average markup over either trend or actual unit labor costs; $u$ is the unemployment rate. Specifications also included a constant, two lags of $\Delta^{2} p_{t-1}$ and either actual or trend labor productivity growth, where trend is measured from a regression of the log of productivity on a time trend, its square, and its cube. 
Table 2: Supply Shocks and Price Inflation

Dependent Variable: $\Delta p_{t}^{C}$

\begin{tabular}{|l|c|c|c|}
\hline & $(1)$ & $(2)$ & $(3)$ \\
\hline$s_{t}^{e n}$ & & $\begin{array}{r}0.135 \\
(0.021)\end{array}$ & $\begin{array}{c}0.129 \\
(0.019)\end{array}$ \\
\hline$s_{t-1}^{e n}$ & & $\begin{array}{c}-0.135 \\
(0.021)\end{array}$ & $\begin{array}{c}-0.105 \\
(0.019)\end{array}$ \\
\hline$s_{t}^{i m}$ & & $\begin{array}{c}0.089 \\
(0.025)\end{array}$ & $\begin{array}{c}0.135 \\
(0.028)\end{array}$ \\
\hline$s_{t-1}^{i m}$ & & $\begin{array}{c}-0.089 \\
(0.025)\end{array}$ & $\begin{array}{c}-.0 .117 \\
(0.028)\end{array}$ \\
\hline$u_{t}$ & $\begin{array}{c}-0.246 \\
(0.185)\end{array}$ & $\begin{array}{c}-0.188 \\
(0.108)\end{array}$ & $\begin{array}{c}-0.290 \\
(0.106)\end{array}$ \\
\hline$u_{t-1}$ & $\begin{array}{c}-0.213 \\
(0.219)\end{array}$ & $\begin{array}{c}-0.299 \\
(0.128)\end{array}$ & $\begin{array}{c}-0.500 \\
(0.136)\end{array}$ \\
\hline$\rho=1$ & & Yes & No \\
\hline $\bar{R}^{2}$ & 0.835 & 0.941 & 0.951 \\
\hline
\end{tabular}

Sample is annual data over 1955-98. $p^{C}$ is the log of the NIPA deflator for Personal Consumption Expenditures, $s_{t}^{e n}$ and $s_{t}^{i m}$ are the logs of the price deflators for energy consumption and imported consumer goods divided by the valued-added deflator for nonfarm business output. Specifications also included a constant and three lags of $\Delta p_{t-1}^{C}$, the coefficients on which were constrained to sum to one. 
Figure 1

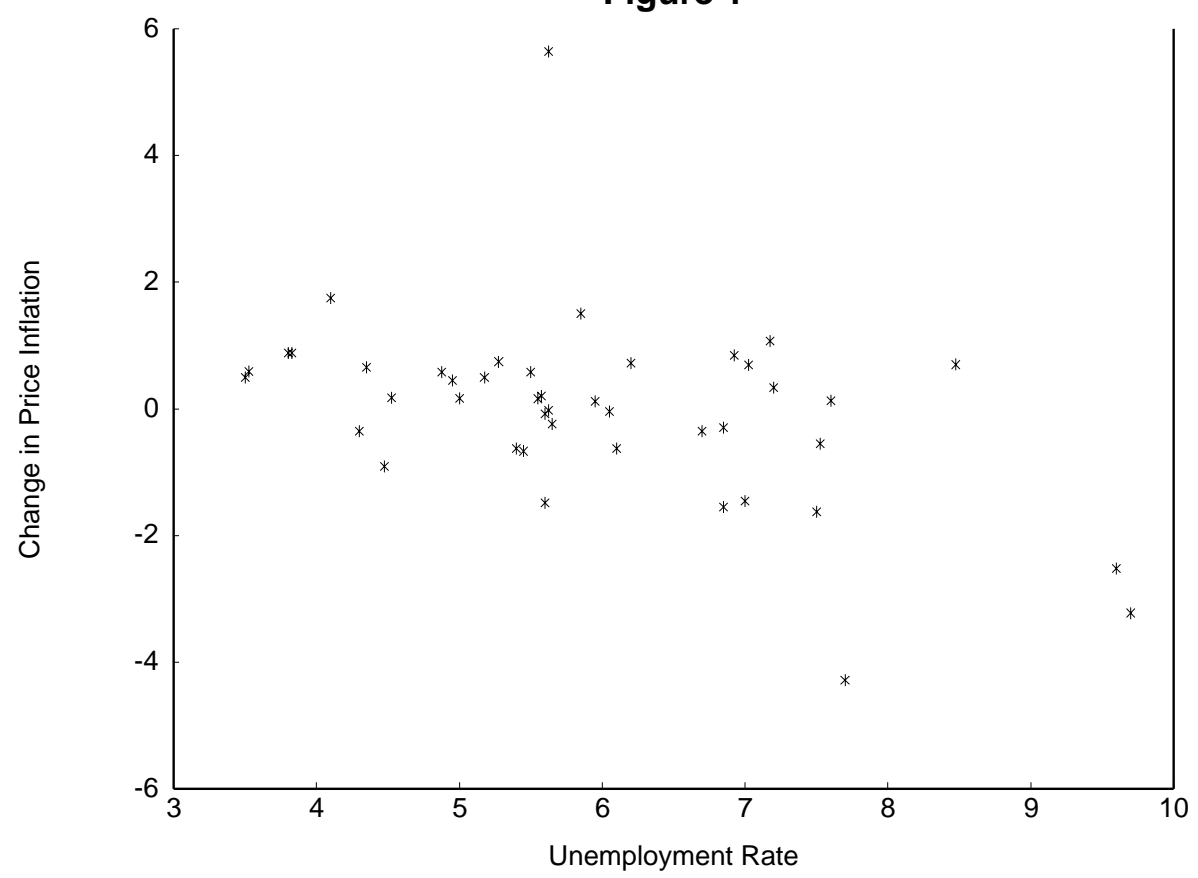

Figure 2

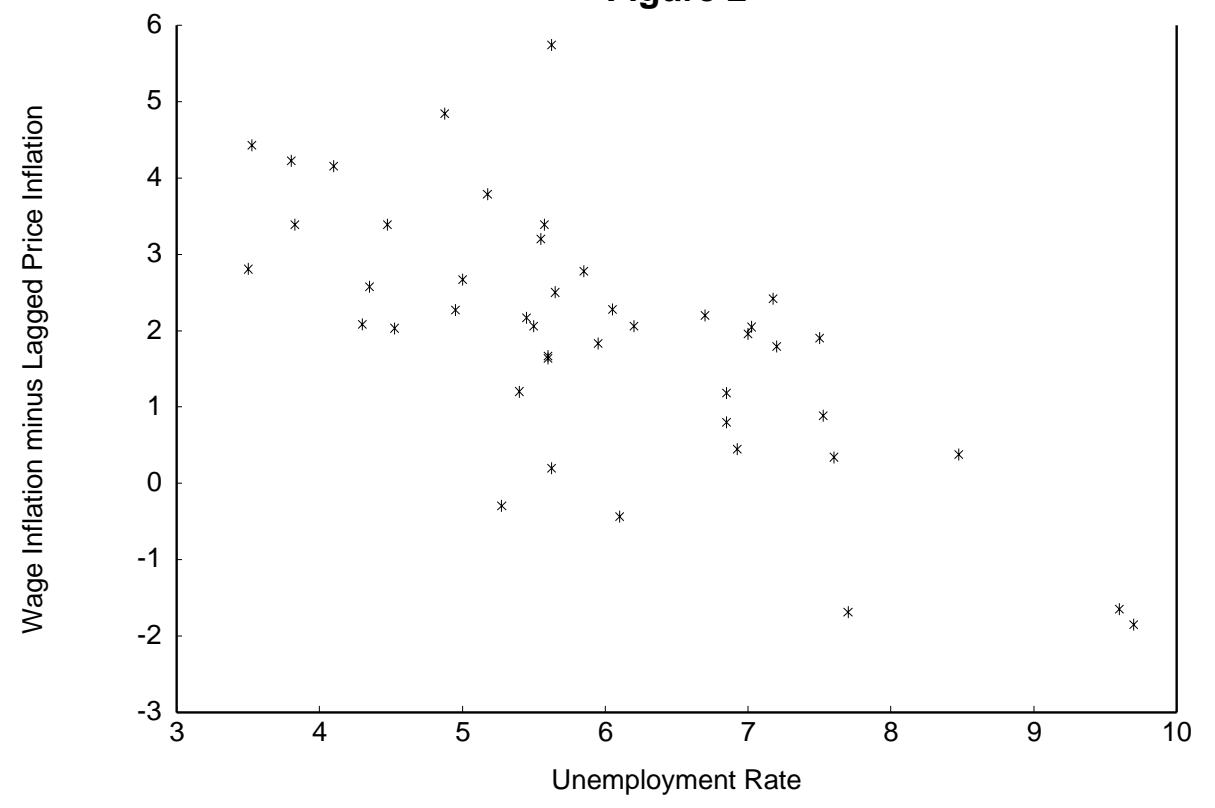


Figure 3

Labor Share for U.S. Nonfarm Business Sector

(NBER Recessions Shaded)

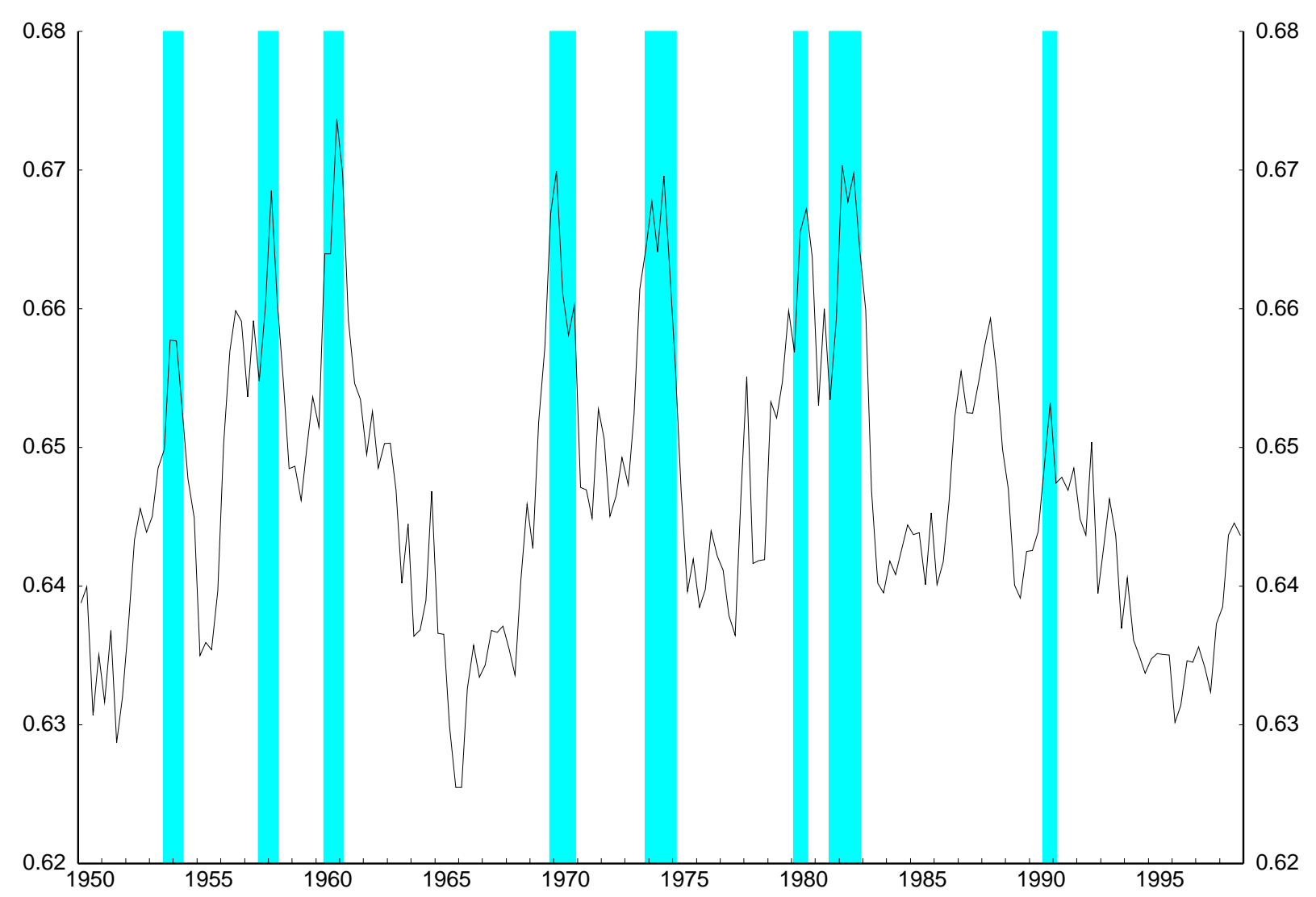


Figure 4

Relative Prices of Energy and Imports

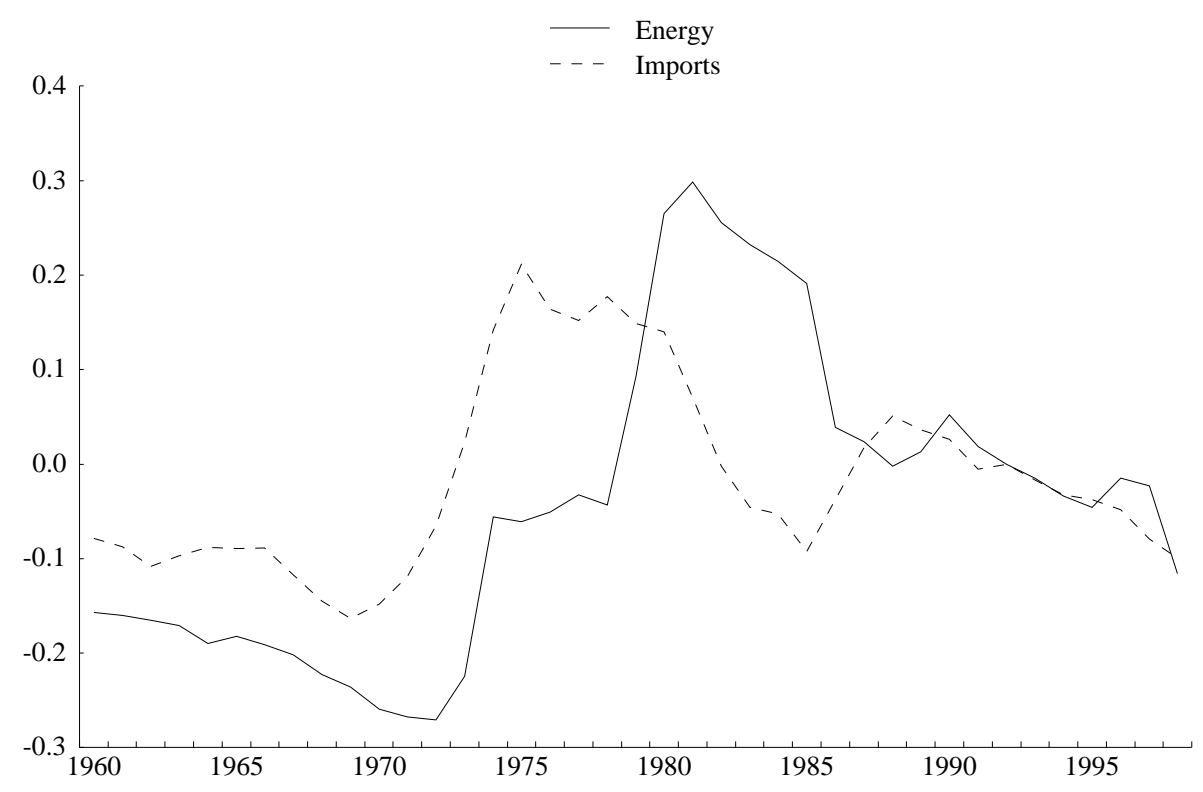

Figure 5

Effect of Supply Shocks on PCE Inflation

Percentage Points (Five-Year Moving Average)

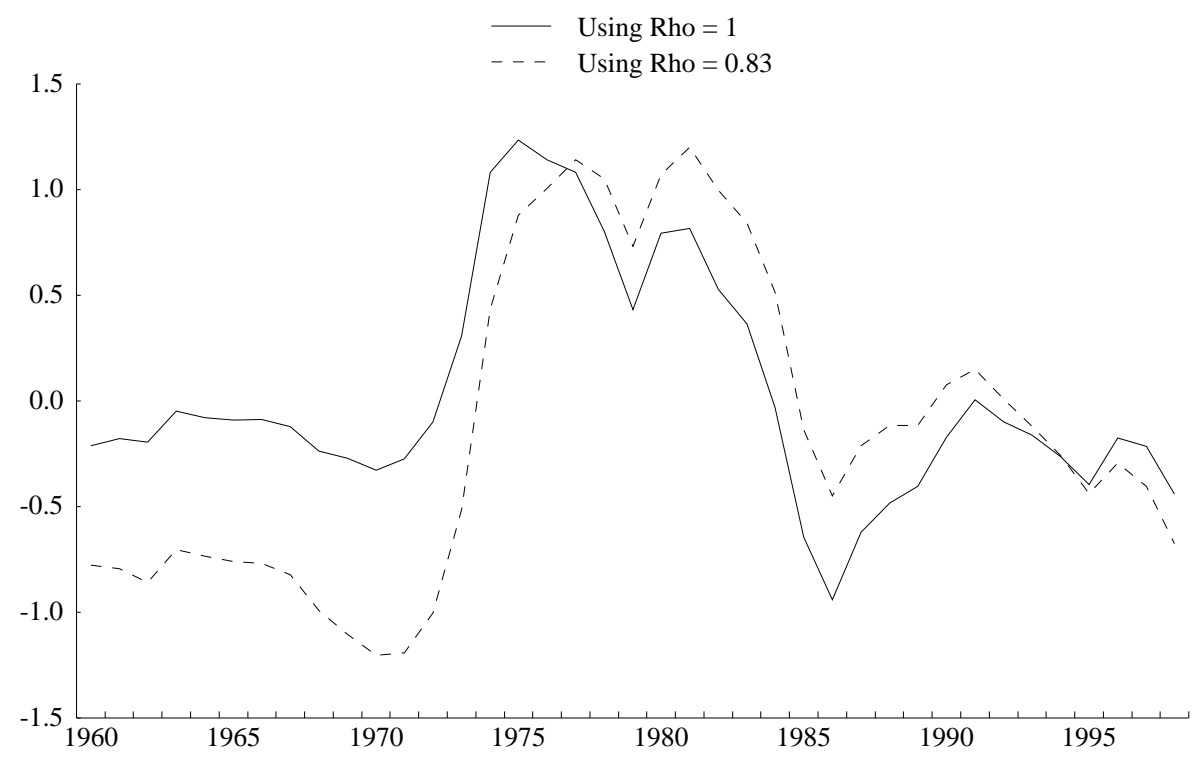


Figure 6

Time-Varying NAIRUs for PCE Inflation

Estimated Using Staiger-Stock-Watson Cubic Spline Method

Using Supply Shocks Based on Rho $=1$

- - Using Supply Shocks Based on Rho $=0.83$

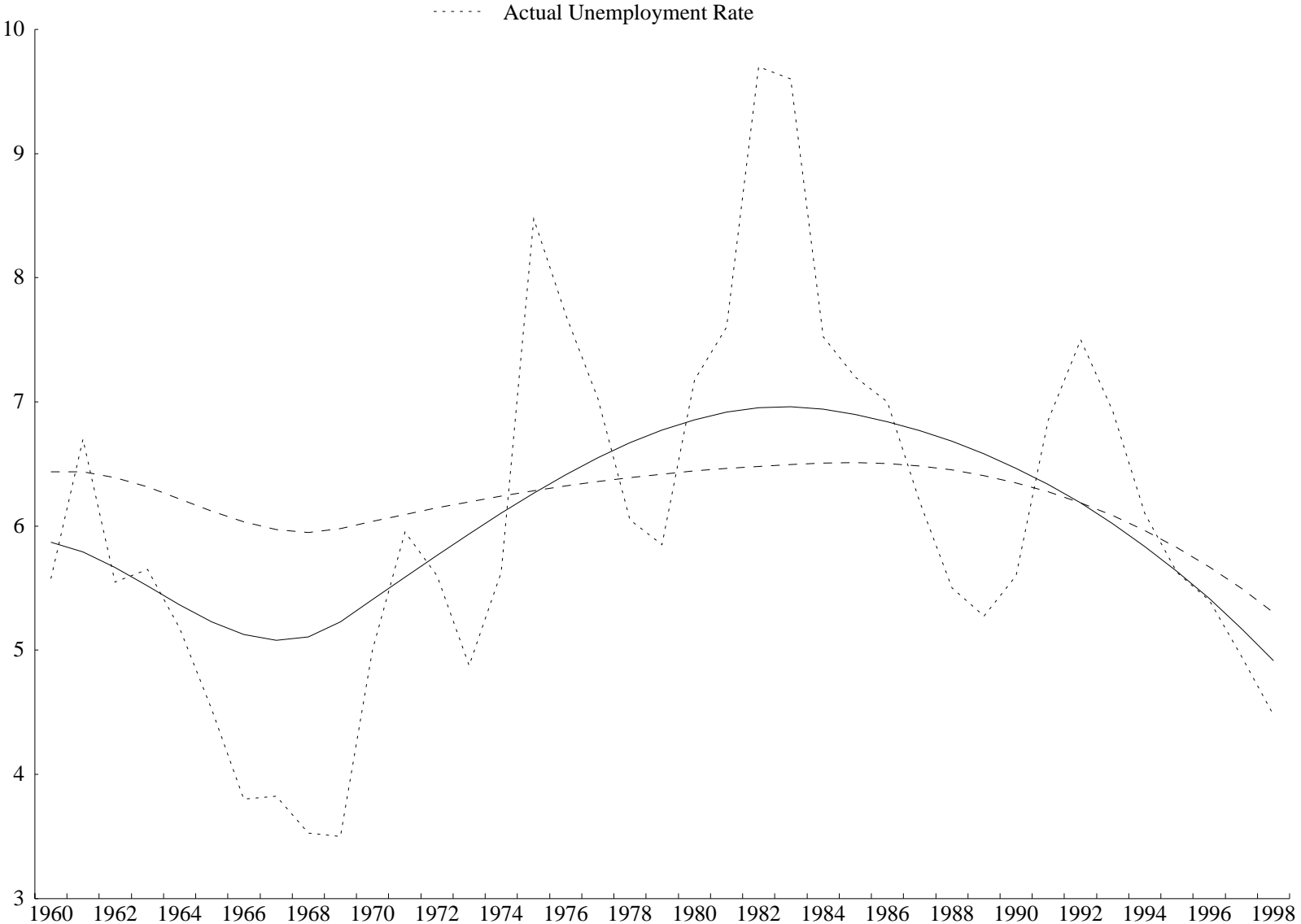

